\title{
Effects of biochar on water movement characteristics in sandy soil under drip irrigation
}

\author{
PU Shenghai ${ }^{1,2,3}$, LI Guangyong ${ }^{1 *}$, TANG Guangmu ${ }^{2,3}$, ZHANG Yunshu ${ }^{2,3}$, XU Wanli ${ }^{2}$, LI \\ Pan $^{2,3}$, FENG Guangping ${ }^{2,3}$, DING Feng ${ }^{2}$ \\ ${ }^{1}$ College of Water Resources and Civil Engineering, China Agriculture University, Beijing 100083, China; \\ ${ }^{2}$ Institute of Soil Fertilizer and Agricultural Water Saving, Xinjiang Academy of Agricultural Sciences, Urumqi 830091, China; \\ ${ }^{3}$ Key Laboratory of Northwest Oasis Agricultural Environment, Ministry of Agriculture of China, Urumqi 830091, China
}

\begin{abstract}
Biochar addition can improve the physical and hydraulic characteristics of sandy soil. This study investigated the effects of biochar on water holding capacity and water movement in sandy soil under drip irrigation. By indoor simulation experiments, the effects of biochar application at five levels $(0 \%, 1 \%, 2 \%$, $4 \%$ and $6 \%$ ) on the soil water retention curve, infiltration characteristics of drip irrigation and water distribution were tested and analyzed. The results showed that biochar addition rate was positively correlated with water holding capacity of sandy soil and soil available water. Within the same infiltration time, with an increasing amount of added biochar, the diffusion distance of the horizontal wetting front (HWF) tended to decrease, while the infiltration distance of vertical wetting front (VWF) initially declined and then rose. The features of wetted bodies changed from "broad-shallow" to "narrow-deep" type. The relationship between the transport distances of HWF and VWF and the infiltration time was described by a power function. At the same distance from the point source, the larger the amount of added biochar, the higher the soil water content. Biochar had a great influence on the water content of the layer with biochar (0-200 $\mathrm{mm}$ ) and had some effects at 200-250 mm without biochar; but it had less influence on the soil water content deeper than $250 \mathrm{~mm}$. For the application rate of biochar of $4 \%$, most water was retained within 0 $250 \mathrm{~mm}$ soil layer. However, when biochar application amount was high (6\%), it would be helpful for water infiltration. During the improvement of sandy soil, biochar application rate of $4 \%$ in the plow layer had the best effect.
\end{abstract}

Keywords: biochar; sandy soil; water holding capacity; water movement; drip irrigation

Citation: PU Shenghai, LI Guangyong, TANG Guangmu, ZHANG, Yunshu, XU Wanli, LI Pan, FENG Guangping, DING Feng. 2019. Effects of biochar on water movement characteristics in sandy soil under drip irrigation. Journal of Arid Land, 11(5): 740-753. https://doi.org/10.1007/s40333-019-0106-6

\section{Introduction}

Globally, land desertification is a serious environmental problem. China is one of the countries with the most serious desertification. By 2014, the desertified land area had reached $1.72 \times 10^{6} \mathrm{~km}^{2}$ in China (SFA PRC, 2014). Land desertification will cause soil texture deterioration, organic matter content reduction, soil structure destruction and water and fertilizer leakage, leading to low soil productivity.

Biochar, known as "black gold" in international academic, was made from organic waste generated in agricultural production through pyrolysis at moderate temperatures (Antal and Gronli,

\footnotetext{
*Corresponding author: LI Guangyong (E-mail: lgycau@163.com)

Received 2018-10-08; revised 2019-03-09; accepted 2019-08-30

C Xinjiang Institute of Ecology and Geography, Chinese Academy of Sciences, Science Press and Springer-Verlag GmbH Germany, part of Springer Nature 2019
} 
2003). It has high carbon content, rich pore structure, large specific surface area, various organic functional groups contained (or absorbed) on the surface, strong ion exchange adsorption capacity and stable physicochemical properties. Biochar addition to sandy soil was considered to improve a range of soil physical and hydraulic properties including soil bulk density (Githinji, 2014; Suliman et al., 2017; Ahmed et al., 2018), soil hydraulic conductivity (Uzoma et al., 2011; Ibrahim et al., 2013; Barnes et al., 2014; Liu et al., 2016; Jacka et al., 2018), water infiltration rate (Ibrahim et al., 2013; Githinji, 2014), soil hydrophobicity (Ibrahim et al., 2013), soil water holding capacity (Dugan et al., 2010; Karhu et al., 2011; Devereux et al., 2012; Liu et al., 2016; Suliman et al., 2017; Al-Wabel et al., 2018), and soil available water (Baronti et al., 2014; Bruun et al., 2014; Glab et al., 2016; Hansen et al., 2016), as well as crop properties including crop production ( Faloye et al., 2017; She et al., 2018), water use efficiency (Xiao et al., 2018) and crop drought resistance (Poormansour and Razzaghi, 2018). The application of biochar improves the physical and hydraulic characteristics of sandy soil (Karhu et al., 2011) and has direct effects on soil water movement. Ibrahim (2013) found that the transport distance of wetting fronts shortened gradually with increased amounts of applied biochar. The transport distance and timing of wetting fronts accorded with a power function (Qi et al., 2015). The Philip infiltration model can be used to describe the changing process of water infiltration in soil with added biochar (Xiao et al., 2015). However, using test results for silty clay loam, Li et al. (2016) suggested that a moderate amount of biochar could reduce the transport velocity of wetting fronts, but a higher amount (4\%) could promote their downward transport. Therefore, researchers studied one-dimensional infiltration of soil mixed with biochar and found that the amount of biochar applied and soil texture were two key factors affecting water movement. Nevertheless, under conditions of water saving, there are few reports on the effects of biochar on three-dimensional water movement in soil. Xu et al. (2015) showed that biochar addition to clay, under conditions of moistube irrigation, remarkably decreased cumulative infiltration capacity, restrained upward water transport and promoted lateral and downward water transport.

Drip irrigation is a high-efficiency water-saving irrigation technique. It has a significant effect on relieving the shortage of agricultural water resource and improving the irrigation water use efficiency. It is very popular and has a large potential application in developing water-saving agriculture (Han et al., 2015). However, there had been little research on the influence of biochar on soil water movement under drip irrigation, and there is a lack of understanding of the infiltration characteristics of drip irrigation water in sandy soil and water distribution with biochar addition. Therefore, the purposes of this study are to set up a gradient of different biochar application rates, to study the effects of biochar on water holding capacity and water movement characteristics under drip irrigation, and to propose appropriate biochar application rate under drip irrigation in the improvement of sandy soil. The results could provide some theoretical basis for study of mechanisms of water migration in "biochar-drip irrigation-sandy soil-crop" systems, and also provide data support for the popularization and utilization of biochar in sandy soil.

\section{Materials and methods}

\subsection{Experimental methods}

Experiments were conducted from October 2017 to January 2018 at the Key Laboratory of Northwest Oasis Agriculture Environment, Ministry of Agriculture, Institute of Soil Fertilizer and Agricultural Water Saving, Xinjiang Academy of Agricultural Sciences of China. The test equipment comprised three main parts: soil box, Markov bottle and medical infusion apparatus (Fig. 1). The soil box was a cube $(565 \mathrm{~mm} \times 565 \mathrm{~mm} \times 585 \mathrm{~mm})$ and was made of 8 -mm thick transparent organic glasses. The Markov bottle was used to provide a constant water pressure. The drip irrigation emitter was simulated by medical infusion apparatus, with the infusion tube connected to a Markov bottle. The drip discharge was adjusted to $1.35 \mathrm{~L} / \mathrm{h}$ by the regulating valve of the infusion tube.

In the experiment, five treatments were set for biochar addition rate at $0 \%(\mathrm{BC} 0$; the control), $1 \%$ 
$(\mathrm{BC} 1), 2 \%(\mathrm{BC} 2), 4 \%(\mathrm{BC} 4)$ and $6 \%(\mathrm{BC} 6)$. There were 3 replicates for each treatment.

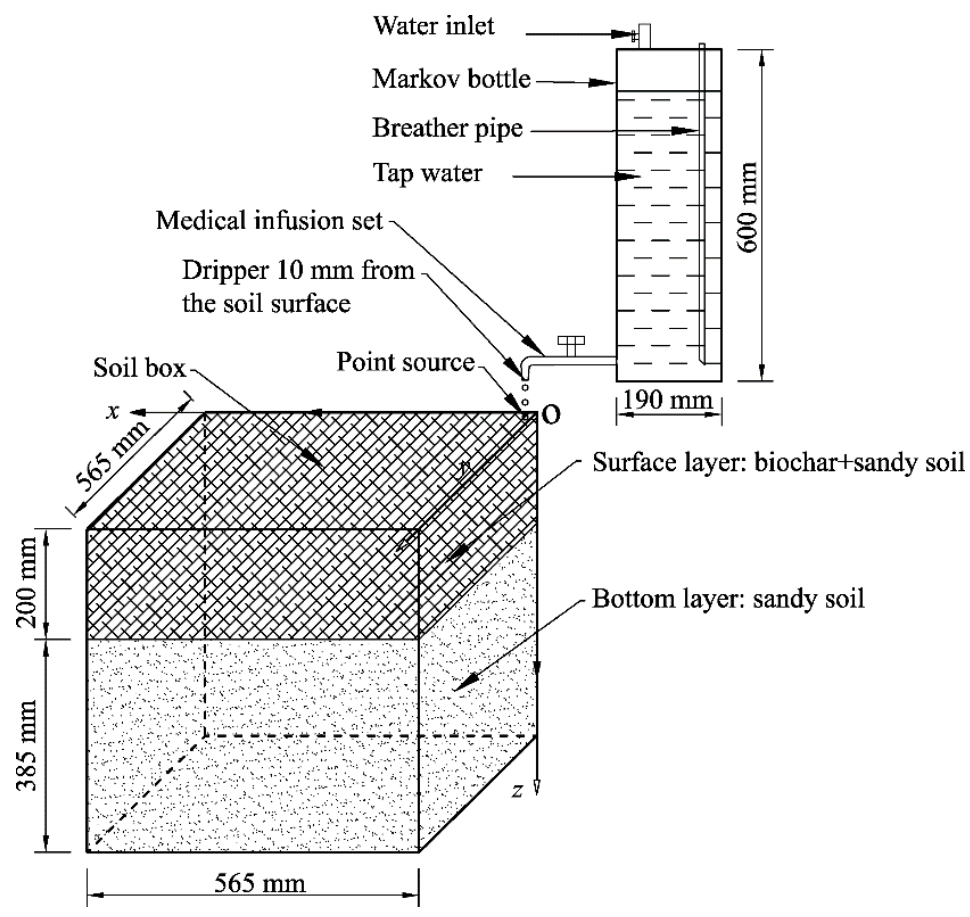

Fig. 1 Schematic diagram of experimental device

The biochar used was a cotton straw biochar product of the Institute of Soil Fertilizer and Agricultural Water Saving, Xinjiang Academy of Agricultural Sciences. Firstly, cotton stalks (water content $<30 \%$ ) were broken into short sections of $10 \mathrm{~cm}$; then, they were heated to $400^{\circ} \mathrm{C}$ at a heating rate of $5^{\circ} \mathrm{C} / \mathrm{min}$ in the carbonization furnace, and maintained at $400^{\circ} \mathrm{C}$ for $3.3 \mathrm{~h}$; finally, the biochar was cooled under anaerobic conditions for at least $16 \mathrm{~h}$. The carbon yield of cotton straw was about $50 \%$. The biochar was ground and passed through a 1-mm sieve. The physical-chemical properties of cotton stalk and biochar are listed in Table 1.

Table 1 Basic physical-chemical properties of cotton stalk, biochar and sand soil

\begin{tabular}{ccccccc}
\hline Material & $\mathrm{pH}$ & \multirow{2}{*}{$\begin{array}{c}\text { Organic } \\
\text { matter }\end{array}$} & $\begin{array}{c}\text { Organic } \\
\text { carbon }\end{array}$ & $\begin{array}{c}\text { Available } \\
\text { nitrogen }\end{array}$ & $\begin{array}{c}\text { Available } \\
\text { phosphorus }\end{array}$ & $\begin{array}{c}\text { Available } \\
\text { potassium }\end{array}$ \\
\cline { 6 - 8 } & & $(\%)$ & $(\%)$ & & $(\mathrm{mg} / \mathrm{kg})$ & \\
\hline Stalk & $6.54 \pm 0.04$ & - & $42.54 \pm 0.90$ & $351.8 \pm 5.1$ & $81.7 \pm 26.0$ & $6548.8 \pm 408.4$ \\
Biochar & $9.71 \pm 0.02$ & $56.42 \pm 0.76$ & $38.57 \pm 0.62$ & $74.3 \pm 0.8$ & $80.1 \pm 1.5$ & $1157.0 \pm 74.3$ \\
Sand soil & $8.54 \pm 0.06$ & $0.21 \pm 0.02$ & $11.92 \pm 1.05$ & $14.9 \pm 1.3$ & $3.1 \pm 0.2$ & $81.0 \pm 6.1$ \\
\hline
\end{tabular}

Note: "-" means no value. Mean \pm SD.

The sandy soil used was collected from the soil improvement experiment station of the $121^{\text {st }}$ Regiment of the $8^{\text {th }}$ Division of Xinjiang Production and Construction Corps, located in the southern rim of Junggar Basin $\left(44^{\circ} 48^{\prime} \mathrm{N}, 85^{\circ} 34^{\prime} \mathrm{E}\right)$. Soil from the surface layer of 0-200 mm was collected, dried naturally and passed through a 2-mm sieve. The soil texture grade was sandy soil, containing $0.27 \%$ clay, $2.58 \%$ silt and $97.15 \%$ sand. According to the designed soil mass ratio, biochar was added into sandy soil to form mixed soils. The bulk density and particle size of the mixed soils are shown in Table 2 .

\subsection{Experimental process}

The sandy soil was backfilled into the bottom layer $(200-585 \mathrm{~mm})$ of the soil box by the bulk density of $1.54 \mathrm{~g} / \mathrm{cm}^{3}$, while the mixed soil with biochar was backfilled to the surface layer (0-20 $\mathrm{mm}$ ) by the weighted bulk density (Table 2). Each layer of soil was $50 \mathrm{~mm}$ thick. We carried out 
coarsen treatment between layers to avoid the structure generated among the soil layers and altering of hydrodynamic characteristics.

Table 2 Physical properties of sand and biochar-sand mixtures as biochar addition increase

\begin{tabular}{ccccc}
\hline \multirow{2}{*}{ Treatment } & \multicolumn{2}{c}{ Grain size composition (\%) } & \multicolumn{2}{c}{ Bulk density } \\
\cline { 2 - 4 } & Slit $(<0.002 \mathrm{~mm})$ & Clay $(0.002-0.020 \mathrm{~mm})$ & Sandy loam $(0.020-2.000 \mathrm{~mm})$ & 1.54 \\
\hline BC0 & 0.27 & 2.58 & 97.15 & 1.53 \\
BC1 & 0.33 & 2.84 & 96.84 & 1.52 \\
BC2 & 0.93 & 2.58 & 96.49 & 1.50 \\
BC4 & 1.19 & 3.74 & 95.06 & 1.47 \\
BC6 & 1.20 & 3.89 & 94.92 & \\
\hline
\end{tabular}

Note: $\mathrm{BC} 0, \mathrm{BC} 1, \mathrm{BC} 2, \mathrm{BC} 4$ and $\mathrm{BC} 6$ indicate that the biochar addition rate were $0 \%, 1 \%, 2 \%, 4 \%$ and $6 \%$, respectively.

We took $1 / 4$ of wetted body of drip irrigation as the research object in this experiment. The drip irrigation emitter was fixed at $10 \mathrm{~mm}$ above the point source $\mathrm{O}$, which is one corner of the soil box, to enable observation of the dynamic migration of the vertical wetting front (VWF) (Li, 2017). The tap water was used for the drip irrigation. In each test, the irrigation amount and emitter discharge remained unchanged, with $4.05 \mathrm{~L}$ and $1.35 \mathrm{~L} / \mathrm{h}$, respectively. The drip irrigation was applied for $3 \mathrm{~h}$ and then the soil surface was immediately covered by thin film to prevent evaporation. The water in wetted bodies was allowed to redistribute for another $3 \mathrm{~h}$. During the whole test process, the time was recorded by a stopwatch. The horizontal wetting front (HWF) in the $x y$-plane and VWF in the $x z$-plane were recorded at different time periods $(1,2,3,4,6,8,10$, $15,20,25,30,40,50,60,70,80,100,120,140,160,190$ and $360 \mathrm{~min})$. With the origin at the point $\mathrm{O}$, the position lines at angles of $0.0^{\circ}(\mathrm{O}-\mathrm{A}), 22.5^{\circ}(\mathrm{O}-\mathrm{B}), 45.0^{\circ}(\mathrm{O}-\mathrm{C}), 67.5^{\circ}(\mathrm{O}-\mathrm{D})$ and $90.0^{\circ}$ $(\mathrm{O}-\mathrm{E})$ with the $x$-axis were marked, respectively. At different time, the transport distances of HWF in five directions (O-A to $\mathrm{O}-\mathrm{E}$ ) were measured directly using a ruler (Fig. 2). The transport distance in the $\mathrm{O}-\mathrm{C}$ direction was chosen as the diffusion length of HWF. On the side wall ( $x z$-plane) of the soil box, the migration trace of VWF was marked. After the test, the transport distances of VWF in nine directions (O-A to $\mathrm{O}-\mathrm{I})$ were determined (Fig. 2). The migration distance in the $\mathrm{O}-\mathrm{I}$ direction served as the infiltration distance of VWF in the test. To understand the characteristics of moisture distribution in wet soil, 14 monitoring points (Fig. 2) were designed on the horizontal plane (xyplane) and stratified sampling in the vertical direction. The interval between layers was $50 \mathrm{~mm}$ until the dry-wet boundary.
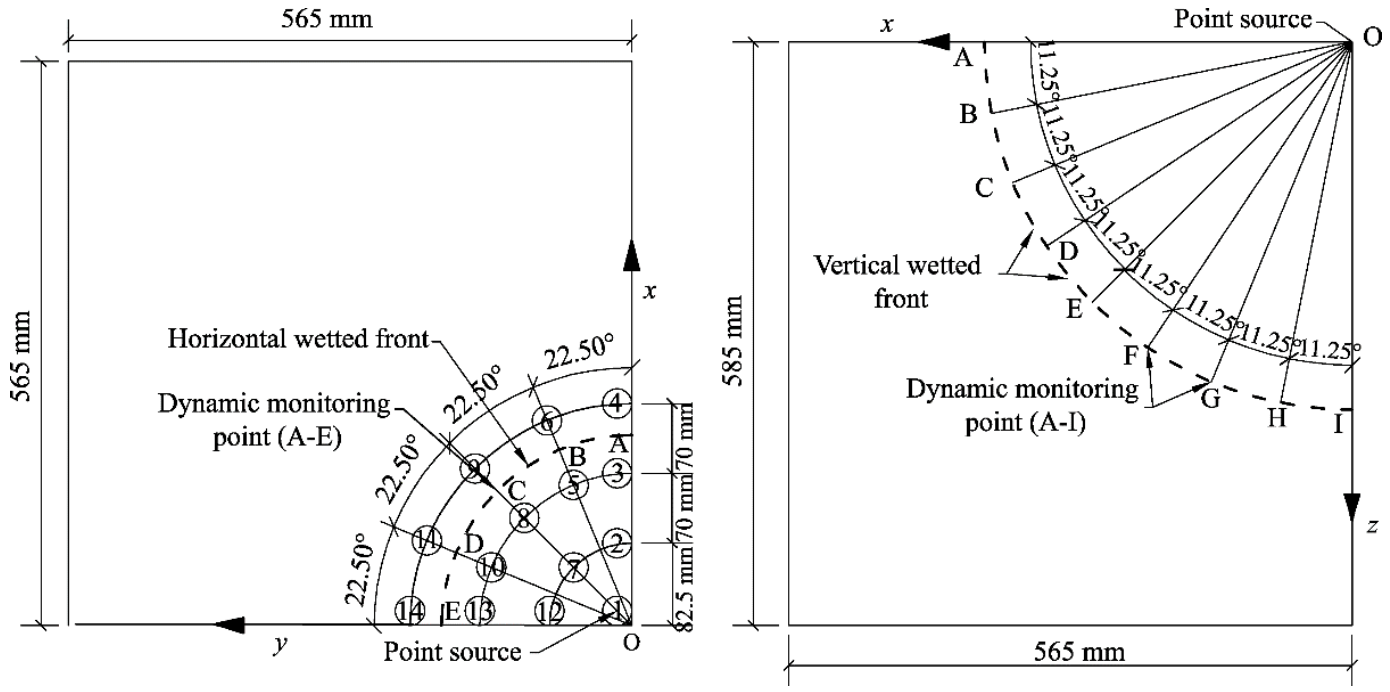

Fig. 2 Horizontal and vertical wetting front dynamic monitoring points and sampling points 


\subsection{Observation index and analysis methods}

Soil water content was regularly measured using the gravimetric method. Soil samples were collected from soil moisture monitoring points and dried at $105^{\circ} \mathrm{C}$ for $8 \mathrm{~h}$. The measurement range of the electronic scale used was $500 \mathrm{~g}$ with an accuracy of $0.01 \mathrm{~g}$. Soil moisture was calculated by Equation 1 (Wang et al., 2017):

$$
\theta=\frac{m_{\mathrm{w}}-m_{\mathrm{d}}}{m_{\mathrm{d}}} \times 100 \%,
$$

where $\theta$ is the soil water content $(\%) ; m_{\mathrm{w}}$ is the mass of wet soil $(\mathrm{g})$; and $m_{\mathrm{d}}$ is the mass of dry soil (g).

The soil water retention curves were measured by centrifuge method (Dong et al., 2016). Before the test, five mixed soils with $0 \%, 1 \%, 2 \%, 4 \%$ and $6 \%$ biochar were added into the cutting ring ( 5 $\mathrm{cm}$ in height and $100 \mathrm{~cm}^{3}$ in volume), respectively, according to the bulk density (Table 2). Three repeated samples were taken for each mixed soil. The height of the sample was not easy to exceed $80 \%$ of the cutting ring height. Each mixed soil was repeated three times. The filled cutting rings were saturated in thin distilled water layer (about $3 \mathrm{~cm}$ ) for at least $24 \mathrm{~h}$. After the sample reached full saturation, the water outside the cutting ring was removed and the sample was weighed. The soil samples to be measured were put into the centrifuge device. The centrifuge speed was set according to the designed soil suction $(0.0,88.8,340.0,530.3,859.0,1053.0,3018.0,5216.0$, 7189.0 and $15,300.0 \mathrm{~cm}$ ), and the centrifuge temperature was constant at $20^{\circ} \mathrm{C}$. At the end of each centrifugation, the total soil weight and the distance from the soil surface to the top of the cutting ring were measured. After the whole process was completed, the samples were dried and weighed to calculate the soil mass water content at various rotational speeds. At the same time, the soil volumetric water content was calculated according to the relationship between the soil volumetric water content and the soil gravimetric water content (Xing et al., 2015).

The four hydrodynamic parameters in the Van-Genuchten model (Eq. 2) were determined by the nonlinear curve fitting method in the software Origin Pro2018C (OriginLab Corporation Northamton, MA 01060 USA).

$$
\theta=\frac{\theta_{\mathrm{s}}-\theta_{\mathrm{r}}}{\left[1+|\alpha h|^{n}\right]^{m}}+\theta_{\mathrm{r}},
$$

where $\theta$ is the volumetric water content $\left(\mathrm{cm}^{3} / \mathrm{cm}^{3}\right) ; \theta_{\mathrm{s}}$ and $\theta_{\mathrm{r}}$ are the saturated and residual soil water content $\left(\mathrm{cm}^{3} / \mathrm{cm}^{3}\right)$, respectively; $\alpha$ is a shape parameter related to the inverse of the air-entry pressure $(1 / \mathrm{cm}) ; h$ is the negative pressure $(\mathrm{cm}) ; n$ is a shape parameter related to the pore-size distribution; and $m$ is the empirical constant affecting the shape of the retention curve and equals to $1-1 / n$ (Ibrahim et al., 2013).

The soil available water (SAW; $\mathrm{m}^{3} / \mathrm{m}^{3}$ ) was the moisture which could be effectively used by the plant in the soil, that is, the difference between the field capacity (FC) and permanent wilting point (PWP). The calculation formula is:

$$
\mathrm{SAW}=\theta_{\mathrm{FC}}-\theta_{\mathrm{PWP}},
$$

where $\theta_{\mathrm{FC}}$ and $\theta_{\mathrm{PWP}}$ are the volumetric water contents $\left(\mathrm{m}^{3} / \mathrm{m}^{3}\right)$ at -100 and $-15,000 \mathrm{~cm}$ (Hardie et al., 2014), respectively.

The particle size was determined by laser particle size analyzer. The organic matter was determined by potassium dichromate oxidation-external heating method. The organic carbon was measured using $\mathrm{K}_{2} \mathrm{Cr}_{2} \mathrm{O}_{7}-\mathrm{H}_{2} \mathrm{SO}_{4}$ oxidation at $170^{\circ} \mathrm{C}-180^{\circ} \mathrm{C}$ followed by titration with $\mathrm{FeSO}_{4}$ solution of $0.2 \mathrm{~mol} / \mathrm{L}$, and the alkali-hydrolysis nitrogen was determined by the diffusion method. Rapid available phosphorus was determined by $\mathrm{NaHCO}_{3}$ solution of $0.5 \mathrm{~mol} / \mathrm{L}$ leachingmolybdenum-antimony colorimetric method. The available potassium was determined by $\mathrm{NH}_{4} \mathrm{OAc}$ solution of $1.0 \mathrm{~mol} / \mathrm{L}$ extraction and flame photometry (Lu, 2000).

Single-factor analysis of variance was applied to the soil hydraulic property parameters and the infiltration test results. Microsoft Excel 2016, Surfer 13.2.438, IBM SPSS 19.0, AutoCAD 2016 
and OriginPro 2018C (OriginLab Corporation Northamton, MA 01060 USA) were used in the statistical analysis and plotting.

\section{Results}

\subsection{Effects of biochar on water holding capacity of sandy soil}

It can be seen from Figure 3 that under the same suction condition, the larger the amount of biochar added, the higher the soil water content. This suggests that biochar improved the water holding capacity of sandy soil. As can be seen from Table 3, the correlation coefficient of the fitted curve under each treatment is greater than 0.98. Therefore, it can be seen that the fitting degree of the parameters of the Van-Genuchten model meets the requirements, and the meaning of the parameters in the model can be used to explain the variation law of the soil water retention curves. By comparing with the control (BC0), biochar application had less effects on $\alpha$ and $n(P>0.05)$, but had significant effects on $\theta_{\mathrm{s}}$ and $\theta_{\mathrm{r}}$. Specifically, the $\theta_{\mathrm{s}}$ increased by $3.60 \%, 4.98 \%$ and $7.26 \%$, and the $\theta_{\mathrm{r}}$ increased by $6.52 \%, 29.97 \%$ and $35.66 \%$ for $\mathrm{BC} 2, \mathrm{BC} 4$ and $\mathrm{BC} 6$, respectively. The biochar application increased the water content at suctions of $-100 \mathrm{~cm}(\mathrm{FC})$ and $-15,000 \mathrm{~cm}(\mathrm{PWP})$. SAW (Table 3) of each treatment increased by $2.32 \%$ (BC1), 3.49\% (BC2), 3.84\% (BC4) and 6.27\% (BC6) compared to the control BC0. Thus, the biochar application effectively increased SAW (Dugan et al., 2010; Karhu et al., 2011; Hansen et al., 2016).

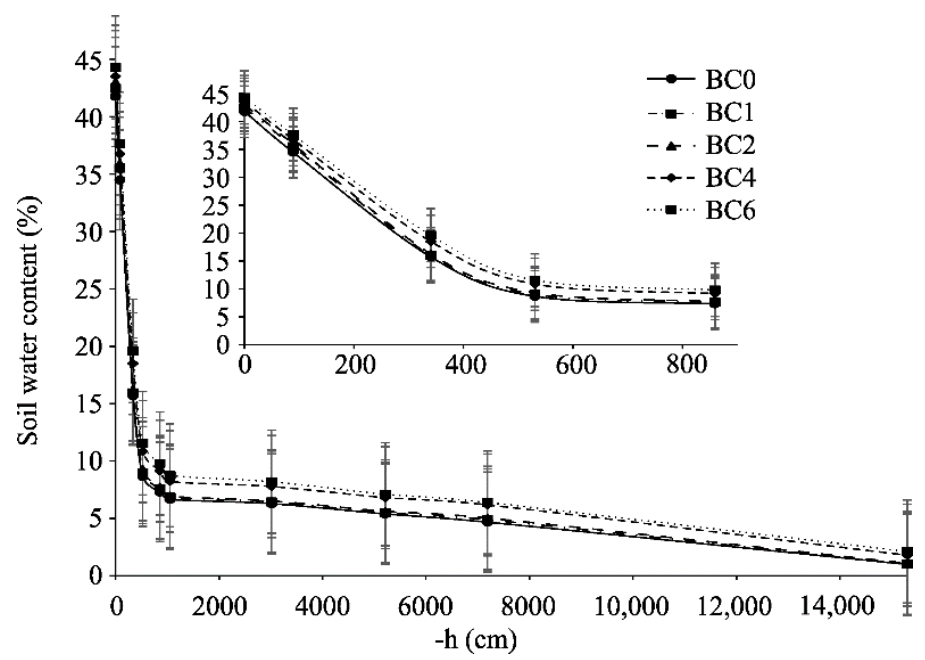

Fig. 3 Effects of biochar on soil water content at different negative pressures $(\mathrm{h} ; \mathrm{cm})$. BC0, BC1, BC2, BC4 and BC6 refer to biochar addition rates at $0 \%, 1 \%, 2 \%, 4 \%$ and $6 \%$, respectively. Bars indicate standard errors.

Table 3 Effects of biochar on dynamic parameters of soil water and SAW

\begin{tabular}{|c|c|c|c|c|c|c|c|c|}
\hline \multirow{2}{*}{ Treatment } & $\theta_{\mathrm{r}}$ & $\theta_{\mathrm{s}}$ & \multirow{2}{*}{$\begin{array}{c}\alpha \\
(1 / \mathrm{cm})\end{array}$} & \multirow{2}{*}{$n$} & \multirow{2}{*}{$R^{2}$} & $\theta_{\mathrm{FC}}$ & $\theta_{\text {PWP }}$ & SAW \\
\hline & \multicolumn{2}{|c|}{$\left(\mathrm{cm}^{3} / \mathrm{cm}^{3}\right)$} & & & & \multicolumn{3}{|c|}{$\left(\mathrm{cm}^{3} / \mathrm{cm}^{3}\right)$} \\
\hline $\mathrm{BC} 0$ & $0.4181^{\mathrm{d}}$ & $0.0369^{b}$ & $0.0079^{\mathrm{a}}$ & $2.1962^{\mathrm{a}}$ & 0.9848 & $0.3326^{\mathrm{d}}$ & $0.0382^{\mathrm{d}}$ & $0.2944^{c}$ \\
\hline $\mathrm{BC} 1$ & $0.4245^{\mathrm{cd}}$ & $0.0386^{b}$ & $0.0077^{\mathrm{a}}$ & $2.2247^{\mathrm{a}}$ & 0.9854 & $0.3410^{\text {cd }}$ & $0.0397^{\mathrm{cd}}$ & $0.3012^{\mathrm{bc}}$ \\
\hline $\mathrm{BC} 2$ & $0.4301^{\mathrm{bc}}$ & $0.0393^{b}$ & $0.0077^{\mathrm{a}}$ & $2.2201^{\mathrm{a}}$ & 0.9857 & $0.3452^{\mathrm{c}}$ & $0.0406^{\mathrm{c}}$ & $0.3046^{\mathrm{b}}$ \\
\hline $\mathrm{BC} 4$ & $0.4347^{\mathrm{ab}}$ & $0.0480^{\mathrm{a}}$ & $0.0075^{\mathrm{a}}$ & $2.1412^{\mathrm{a}}$ & 0.9818 & $0.3554^{\mathrm{b}}$ & $0.0498^{\mathrm{b}}$ & $0.3057^{\mathrm{ab}}$ \\
\hline BC6 & $0.4423^{\mathrm{a}}$ & $0.0501^{\mathrm{a}}$ & $0.0073^{\mathrm{a}}$ & $2.1195^{\mathrm{a}}$ & 0.9820 & $0.3651^{\mathrm{a}}$ & $0.0522^{\mathrm{a}}$ & $0.3128^{\mathrm{a}}$ \\
\hline$P$ value & 0.0041 & 0.0011 & 0.0004 & 0.0558 & na & 0.0038 & 0.0010 & 0.0033 \\
\hline
\end{tabular}

Note: $\theta_{\mathrm{s}}$ and $\theta_{\mathrm{r}}$ are the saturated and residual soil water content $\left(\mathrm{cm}^{3} / \mathrm{cm}^{3}\right)$, respectively; $n$, a shape parameter related to the pore-size distribution; $\theta_{\mathrm{FC}}$ and $\theta_{\mathrm{PWP}}$ are the soil volumetric water contents $\left(\mathrm{m}^{3} / \mathrm{m}^{3}\right)$ at -100 and $-15,000 \mathrm{~cm}$ (Hardie et al., 2014), respectively; SAW, soil available water; na, not applicable. Values followed by different lowercase letters within a column are significantly different at $P<0.05$ level using the least significant difference test.

\subsection{Effects of biochar on infiltration characteristics of drip irrigation}

Figure 4 presents the effects of biochar on the HWF diffusion. Figures $4 \mathrm{a}$ and $\mathrm{b}$ are the contrast 
analysis diagrams of HWF in the case of dripping within $10 \mathrm{~min}$ and the whole process, respectively. The overall trend was that, within the same infiltration time, as the biochar addition rate increased, the diffusion distance of HWF gradually declined in the order of $\mathrm{BC} 0>\mathrm{BC} 1>\mathrm{BC} 2>\mathrm{BC} 4>\mathrm{BC} 6$. Thus, the biochar addition reduced water diffusivity in the horizontal direction. With increased biochar addition rate, VWF initially decreased and then increased as the order of $\mathrm{BC} 6>\mathrm{BC} 0>\mathrm{BC} 1>\mathrm{BC} 2>\mathrm{BC} 4$ (Fig. 5). When the biochar additive proportion was low $(\leq 4 \%)$, there was a negative correlation between VWF and biochar addition rate. However, with the higher biochar addition rate $(6 \%)$, VWF was obviously higher than that with the lower biochar addition rate $(\leq 4 \%)$. Thus, a certain biochar addition rate contributed to restraining vertical water infiltration, but excess biochar addition increased vertical water infiltration. A power function, $D=\mathrm{a} t^{\mathrm{b}}$ ( $D$, the distance of HWF or VWF; $t$, the time corresponding to the migration distance of HWF or VWF; and $a$ and $b$ are the curve fitting parameters), was fitted to all the relationships of infiltration time with transport distances of HWF and VWF, with $R^{2}$ values $>0.86$ (Table 4).
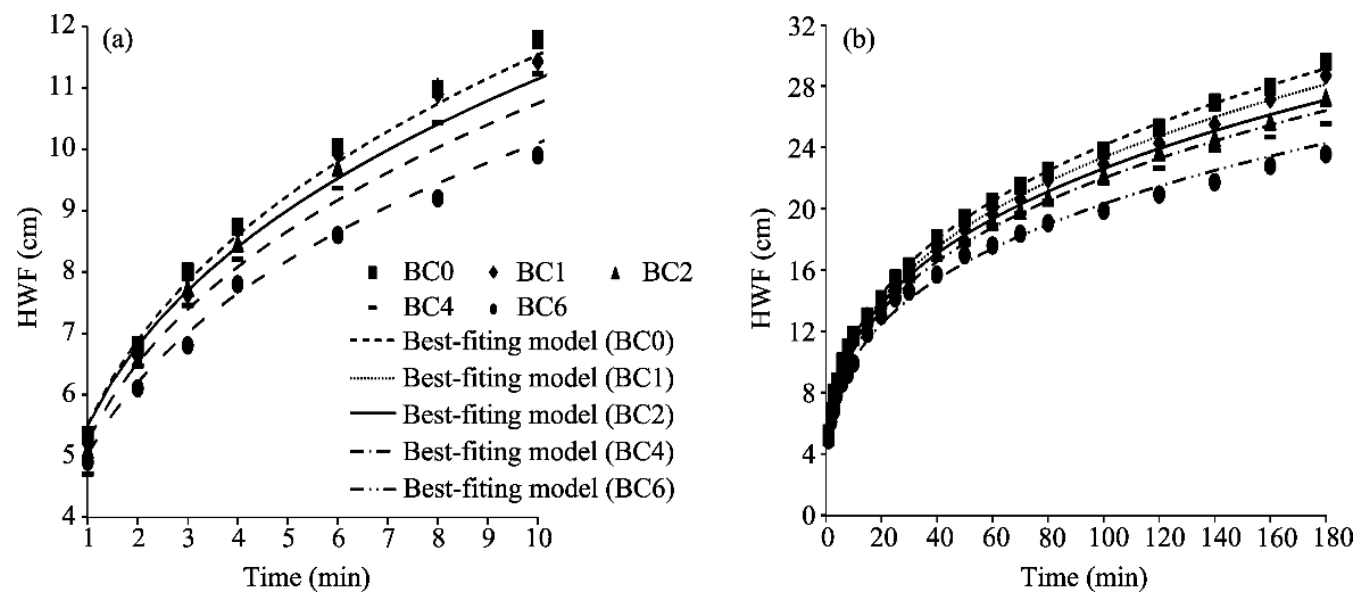

Fig. 4 Effects of biochar on horizontal wetting front (HWF), represented by the power function $\left(D=\mathrm{a} t^{\mathrm{b}}\right.$, where $D$ is the distance of HWF or VWF (vertical wetting front), $t$ is the time corresponding to the migration distance of HWF or VWF, and $a$ and $b$ are curve fitting parameters)

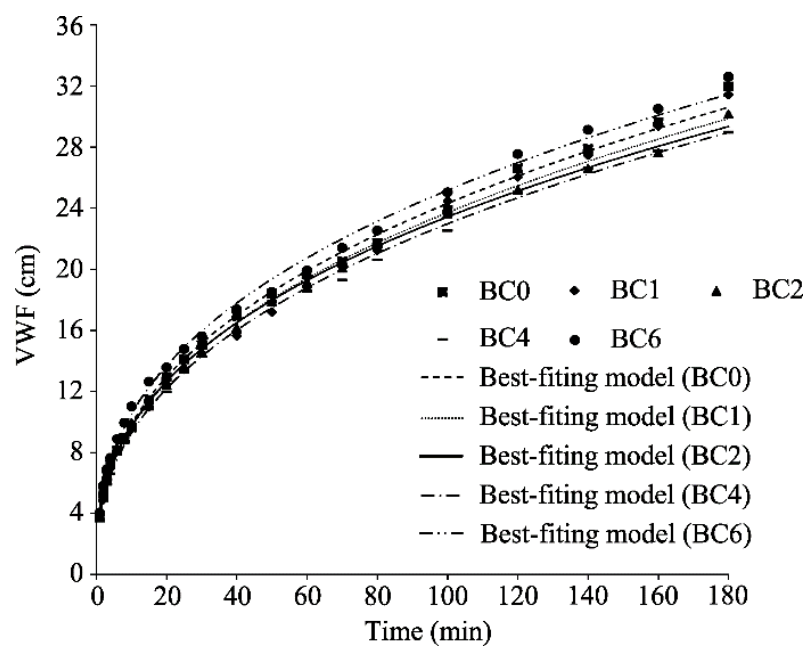

Fig. 5 Effects of biochar on vertical wetting front (VWF), represented by the power function $\left(D=a t^{b}\right)$

To understand the effect of biochar on the characteristics of wetted bodies in sandy soil under drip irrigation, we compared the ratios HWF to VWF for the treatments. The ratios of each treatment tended to decrease with the infiltration time (Fig. 6). Thus, in the infiltration process, the decrease of migration rate of $\mathrm{HWF}$ was relatively greater than that of vertical infiltration rate. There were obvious differences in the critical time points $(\mathrm{BC} 0(93 \mathrm{~min})>\mathrm{BC} 1(80 \mathrm{~min})>\mathrm{BC} 2(62$ 
$\min )>B C 4(54 \mathrm{~min})>B C 6(6 \mathrm{~min}))$ at which the ratio of each treatment was equal to 1 . This indicates that the biochar addition significantly affected the features of wetted bodies. Within the same infiltration time, the larger the amount of added biochar, the smaller the ratio. At the moment of ceasing the drip irrigation, compared with $\mathrm{BC} 0$, the ratios reduced by $1.37 \%, 2.41 \%, 4.71 \%$ and $21.91 \%$ under BC1, BC2, BC4 and BC6 (Fig. 7), respectively. At the end of water redistribution (3 $\mathrm{h}$ after drip irrigation ceasing), the ratios reduced by $4.27 \%, 7.09 \%, 10.93 \%$ and $25.04 \%$ under $\mathrm{BC} 1, \mathrm{BC} 2, \mathrm{BC} 4$ and $\mathrm{BC} 6$, respectively. For the $\mathrm{BC} 6$ treatment, the reduction was the most remarkable, mainly due to minimum diffusion distance in the horizontal direction and maximum infiltration distance in the vertical direction (Figs. 4 and 5). Therefore, with the increased amount of biochar added, the features of wetted bodies formed by drip irrigation in sandy soil changed from "broad-shallow" to "narrow-deep" type.

Table 4 Mathematical model of the horizontal wetting front (HWF) and vertical wetting front (VWF) over time

\begin{tabular}{|c|c|c|c|c|c|c|c|c|c|}
\hline \multirow{3}{*}{ Treatment } & \multicolumn{9}{|c|}{$D=\mathrm{a} t^{\mathrm{b}}$} \\
\hline & \multicolumn{3}{|c|}{ HWF } & \multicolumn{3}{|c|}{ VWF } & \multicolumn{3}{|c|}{ HWF/VWF } \\
\hline & $\mathrm{a}$ & $\mathrm{b}$ & $R^{2}$ & $\mathrm{a}$ & $\mathrm{b}$ & $R^{2}$ & $\mathrm{a}$ & $\mathrm{b}$ & $R^{2}$ \\
\hline $\mathrm{BC} 0$ & 5.5193 & 0.3205 & 0.9990 & 3.9986 & 0.3919 & 0.9983 & 1.3795 & -0.0710 & 0.9615 \\
\hline $\mathrm{BC} 1$ & 5.4474 & 0.3161 & 0.9983 & 3.8850 & 0.3928 & 0.9970 & 1.4058 & -0.0780 & 0.9415 \\
\hline $\mathrm{BC} 2$ & 5.4931 & 0.3074 & 0.9962 & 4.0228 & 0.3823 & 0.9983 & 1.3711 & -0.0770 & 0.9453 \\
\hline $\mathrm{BC} 4$ & 5.2539 & 0.3110 & 0.9951 & 3.7404 & 0.3942 & 0.9983 & 1.4138 & -0.0860 & 0.9562 \\
\hline BC6 & 5.0243 & 0.3034 & 0.9962 & 4.3911 & 0.3792 & 0.9968 & 1.1531 & -0.0790 & 0.8614 \\
\hline
\end{tabular}

Note: $D$, the distance of HWF or VWF; $t$, the time corresponding to the migration distance of HWF or VWF; a and $\mathrm{b}$, curve fitting parameters.

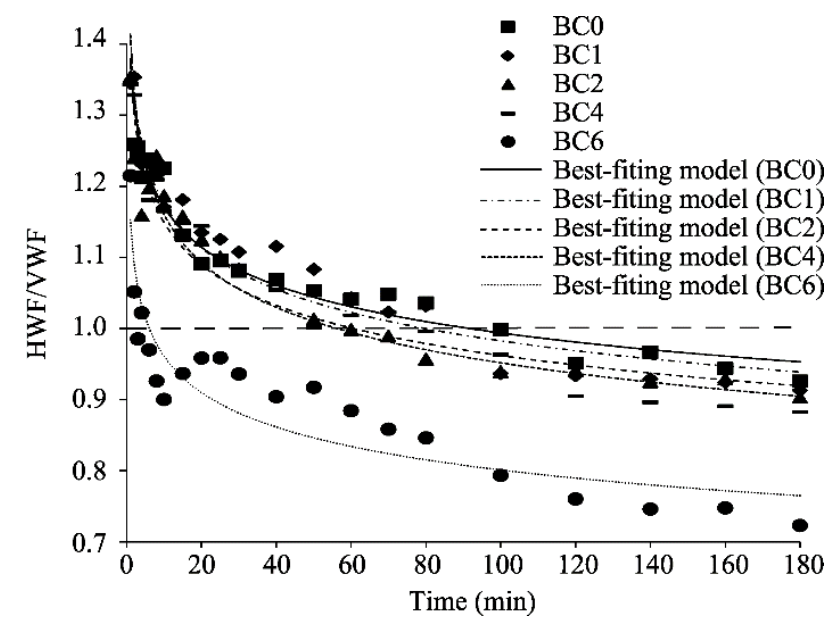

Fig. 6 Dynamic variation of HWF/VWF, represented by the power function $\left(D=\mathrm{a} t^{\mathrm{b}}\right)$

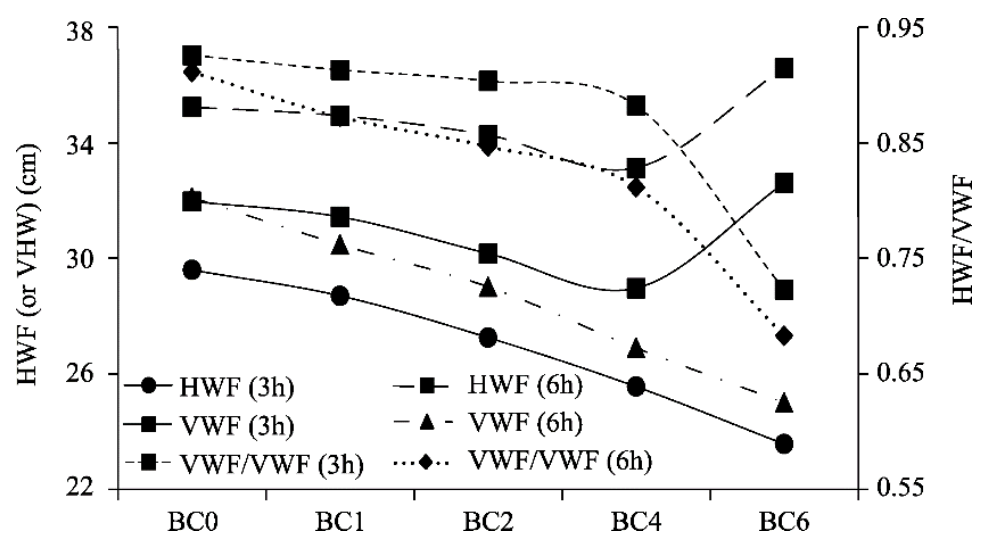

Fig. 7 Effects of biochar on HWF/VWF, represented by the power function $\left(D=\mathrm{a} t^{\mathrm{b}}\right)$ 


\subsection{Effects of biochar on distribution of soil water}

The effects of different biochar addition rates on water distribution ( $3 \mathrm{~h}$ after ceasing drip irrigation) in wetted bodies were analyzed. The soil layer at a depth of 150-200 $\mathrm{mm}$ was chosen for typical analysis. The reason is that this layer was the layer of soil that was mixed with biochar with relatively large water content, and in the other soil layers, the water distribution characteristics were similar. Figure 8 shows the contour maps of water distribution in the horizontal direction of the soil layer of $150-200 \mathrm{~mm}$ (the variation trend of $\mathrm{BC} 1$ was consistent with the analysis results, for conciseness, the contour map was omitted). In the horizontal direction, the water distribution was manifest as the soil water content initially increasing and then decreasing with increased distance from the point source. The maximum water content of each treatment was at $7 \mathrm{~cm}$ from the point source (Figs. 8 and 9). At the same distance from the point source, the larger was the biochar addition rate, the higher was the water content and this phenomenon was most obvious in the region with high water content at soil depth around $70 \mathrm{~mm}$ (Fig. 9).
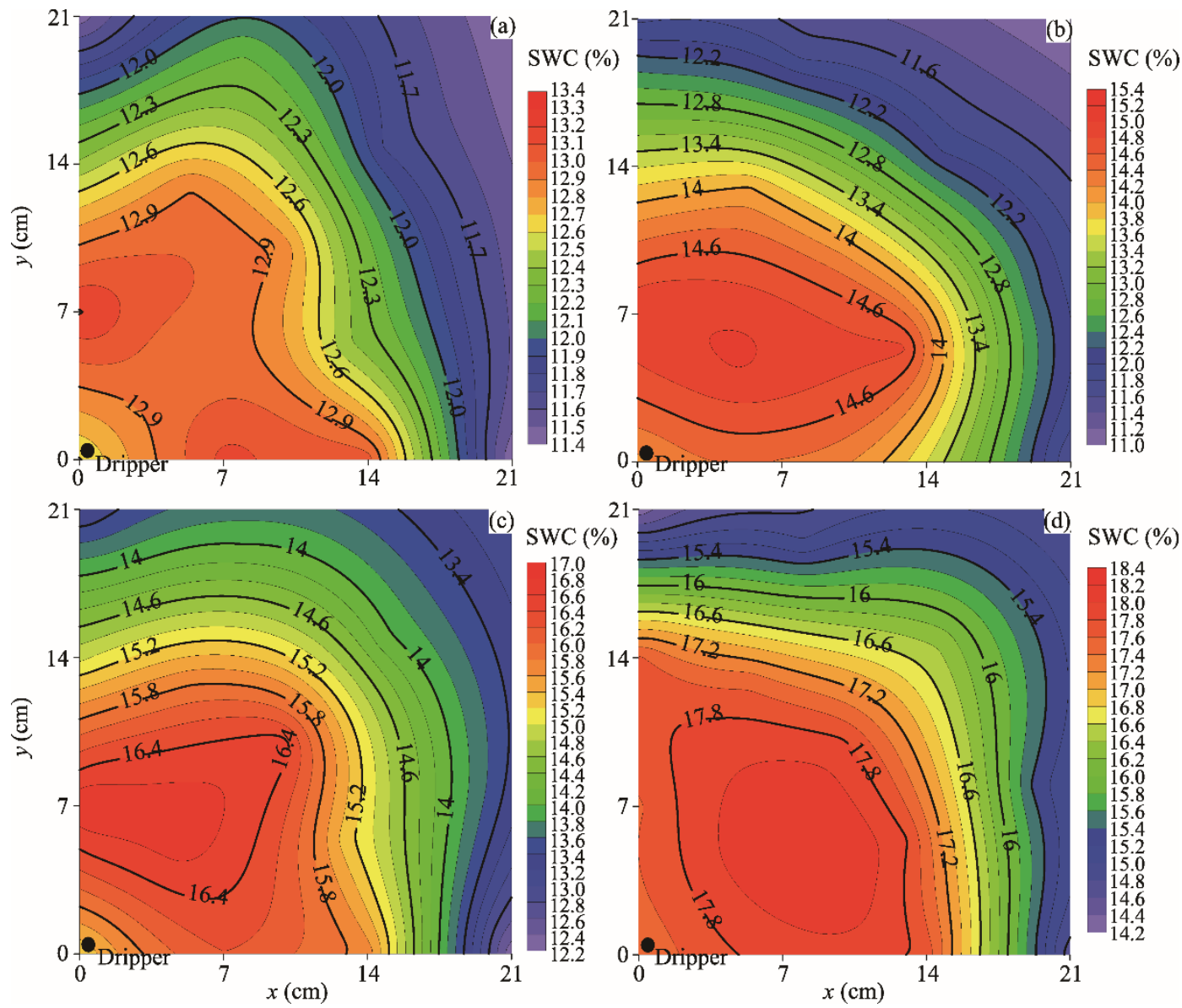

Fig. 8 Contour map of soil water content (SWC) in soil layer of 150-200 mm. (a), BC0; (b), BC2; (c), BC4; (d), BC6.

To understand the water distribution in the vertical direction, we selected the vertical section with an angle of $45^{\circ}$ to the $x$-axis (CZ-plane) for typical analysis. Figure 10 shows the contour maps of water distribution in the vertical section (the variation trend of $\mathrm{BC} 1$ was consistent with the analysis results, for conciseness, the contour maps was omitted). The water distribution characteristics of each treatment in the vertical direction were that soil water content initially increased and then declined with depth. Comparing with $\mathrm{BC} 0$, the soil water distribution in the treated layer was relatively even (Fig. 11). The major reasons for this were the weak water-retaining 
capacity of sandy soil and strong vertical infiltration ability. As a result, the water was quickly distributed in all soil layers and the maximum mass water content was only $13.65 \%$ in the whole wetted body.

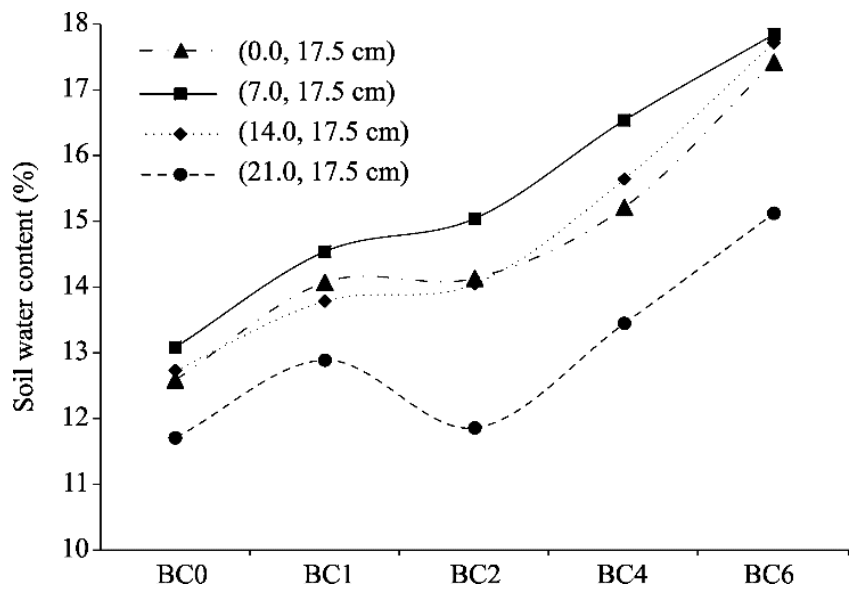

Fig. 9 Effects of biochar on water distribution in the horizontal direction. Values in the bracket denote coordinates of analytic points.
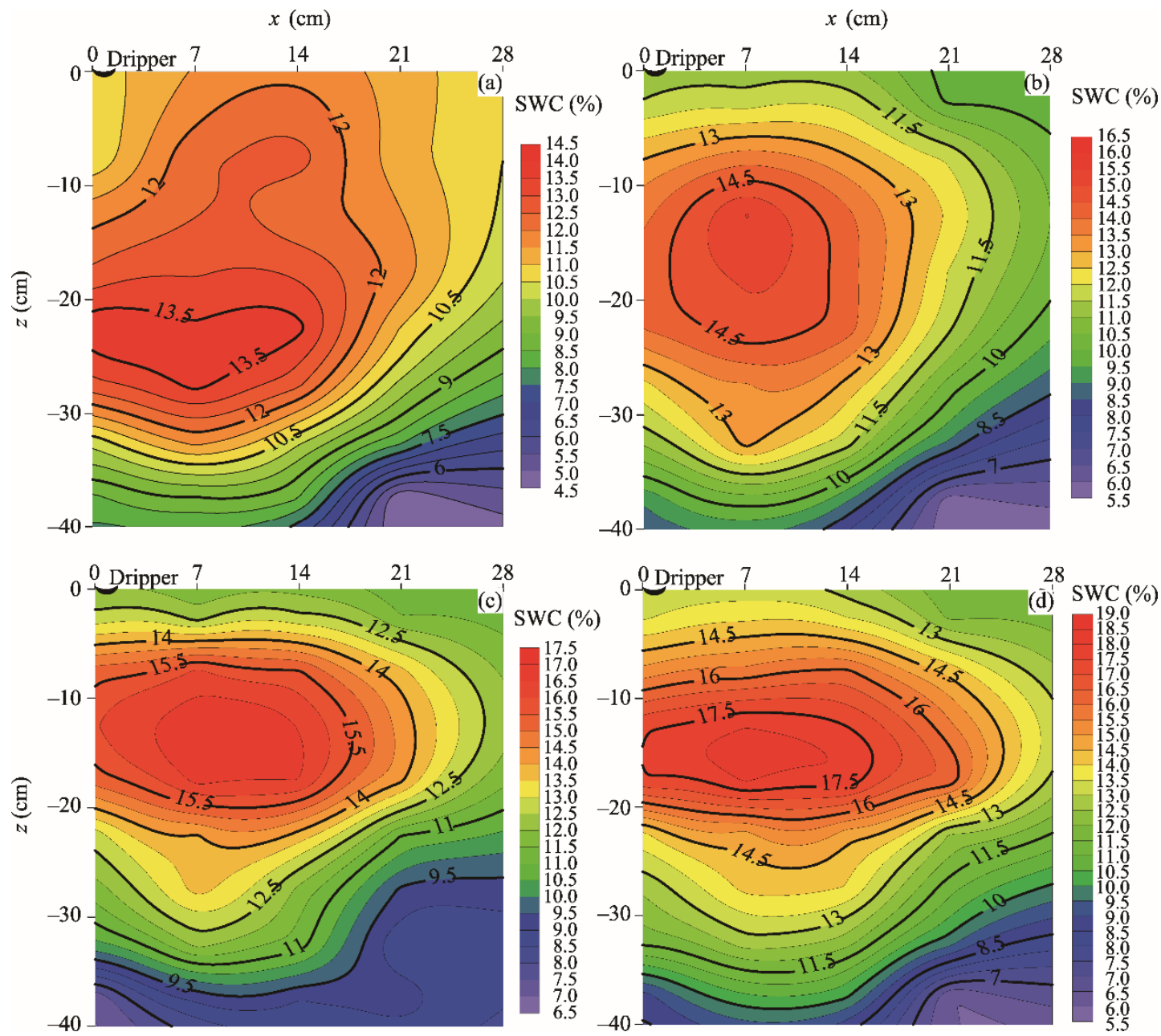

Fig. 10 Contour map of soil water content in the vertical section of $45^{\circ}$ (CZ-plane). (a), BC0; (b), BC2; (c), BC4; (d), BC6. 


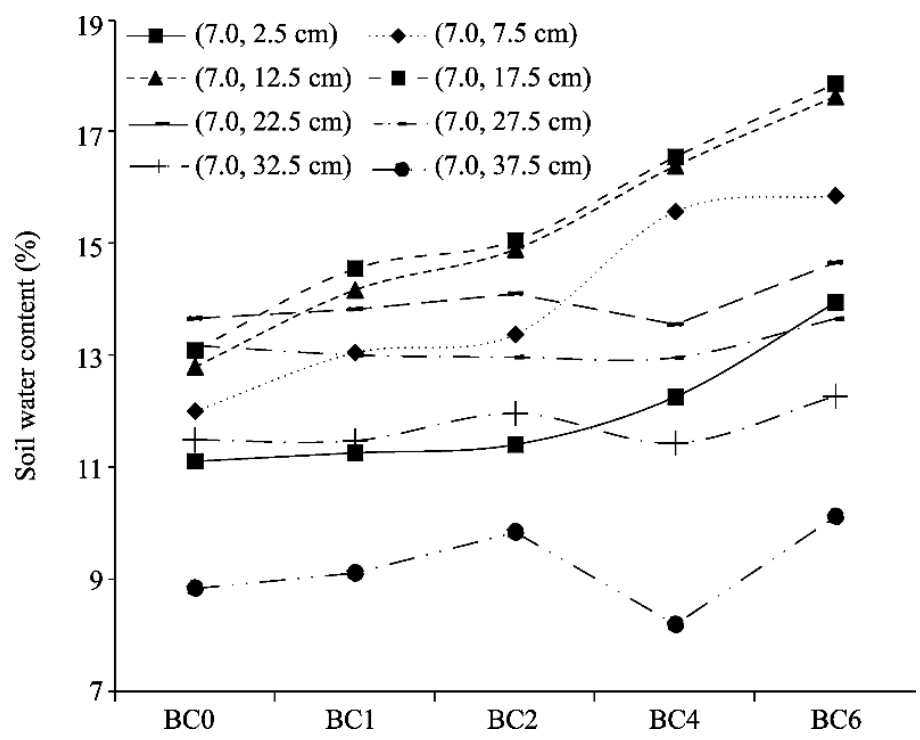

Fig. 11 Effects of biochar on water distribution in the vertical direction. Values in the bracket denote coordinates of analytic points.

After the biochar addition, the soil layer of 150-200 $\mathrm{mm}$ had the maximum water content for each treatment, followed by the layers of 50-100 and 200-250 mm, and 0-5 and 250-400 $\mathrm{mm}$. The water distribution characteristics would help to retain most moisture in the layer of $0-250 \mathrm{~mm}$ and effectively prevent leakage in deep layers. The biochar had a strong effect on the water distribution of layers within $0-200 \mathrm{~mm}$. At the same position, the larger was the rate of biochar addition, the higher is the water content. Compared to the layer without biochar, the biochar addition had a certain effect on the water content in the layer of 200-250 mm, but it had less influence below 250 $\mathrm{mm}$. Further comparison of water content characteristics of each treatment for the layer 250-400 $\mathrm{mm}$ showed that, at the same position, $\mathrm{BC} 4$ had the lowest water content and BC6 had the highest. Thus, BC4 better retained water within 0-250 mm (i.e., the plow layer) and restrained water infiltration. Consequently, the application of biochar at $4 \%$ is recommended.

\section{Discussion}

Biochar agricultural use has been reported as a soil amendment at home and abroad, but the quantitative relationship between the biochar addition rate and the water holding capacity of desertified soil is still unclear.The water holding capacity of biochar itself is strong (the test biochar was produced from cotton straw with a water holding capacity of $173 \%$ ). Biochar addition can significantly improve the water holding capacity of sandy soil and increase the soil available water (increased by $6.27 \%$ under BC6 treatment compared with $\mathrm{BC} 0$ ). These results are consistent with those of Blanco-Canqui and Ibrahim (Ibrahim et al., 2013; Blanco-Canqui, 2017). In comparison, biochar treatment had a greater impact on saturated moisture content, with BC4 and BC6 increased by $29.97 \%$ and $35.66 \%$, respectively, which agreed with the findings of Wang (2013). The increase in saturated moisture content means that under the same environment, the application of biochar can better maintain a certain amount of water and the soil water holding capacity can be effectively improved. Therefore, as a soil conditioner, biochar can not only increase the water holding capacity of sandy soil, but also realize the resource utilization of agricultural straw waste. It has prospects of wide application (Liu et al., 2018).

Biochar can change the distribution and quantity of soil pore structure, which in turn affects soil water infiltration. The effect of biochar on soil water infiltration characteristics depends on the soil texture type. Qi et al. (2015) believed that biochar can reduce the water infiltration capacity of sandy soil, which was not completely consistent with the results of this experiment. Biochar addition can restrain the lateral water migration in sandy soil (Wang et al., 2018). In the vertical 
direction, the water infiltration rate initially declined and then increased with the increased biochar application. The main cause was that a moderate amount of biochar can fill macropores between sand grains and block part of the original soil drainage, thereby reducing vertical infiltration. When the biochar addition was high, the biochar particles could form new and clear drain channels, and therefore promote vertical infiltration.

The water movement characteristics under drip irrigation is the theoretical basis for drip irrigation engineering design. After biochar addition, the relatively uniform distribution characteristics of water of wetted bodies in the original sandy soil were changed. Most water could be retained in the plow layer, and water leakage in the deep layer was restrained, particularly for the biochar addition of 4\%. However, when the biochar addition rate was large (e.g., 6\%), this contributed to water vertical infiltration and cause water leakage in the deep layer. It is necessary to further study the effects on water vertical infiltration in sandy or coarse soils, using high biochar addition rate (e.g., $6 \%-10 \%(\mathrm{w} / \mathrm{w})$ ). The effects of biochar addition on water movements under drip irrigation were clear and this will be beneficial to improve the water regime in sandy soil using drip irrigation and enhance water use efficiency (Kangoma et al., 2017) and drought resistance of crops.

\section{Conclusions}

In sand soil, biocarbon addition can significantly increase soil water holding capacity and soil available water, which will facilitate crop growth. Within the same infiltration time, with the increased rate of biochar addition, the diffusion distance of HWF tended to reduce, but VWF initially declined and then increased. A certain biochar added proportion was beneficial to slow the infiltration rate in the vertical direction, but excessive addition improved vertical infiltration. At the same distance from the point source, the larger was the biochar addition rate, the higher was the soil water content. The biochar had large effects on the layer within 0-200 $\mathrm{mm}$. A biochar application amount of $4 \%$ is recommended for improvement of sandy soil. It is recommended that the test soil biochar application is $4 \%$, so that more irrigation water can be maintained at $0-250$ $\mathrm{mm}$ (the tillage layer) to reduce deep leakage.

The indoor experimental comparisons showed effects of biochar addition on water movement under drip irrigation in sandy soil. This provides a theoretical basis for further researches on the water migration mechanism in the "biochar-drip irrigation-sandy soil-crop" system. However, the water movement characteristics are greatly affected by environmental or biological factors, such as macropores formed by earthworms and ants. In the screening process, particles larger than 2.000 $\mathrm{mm}$ were removed from the tested soil, which greatly decreased the number of macropores. The compaction process also seriously changes the natural soil structure. Therefore, there may be some differences between the test results and the practical situation. Further field trials are required to assess such potential problems to determine the potential productivity of biochar addition in sandy or coarse soil.

\section{Acknowledgements}

This research was supported by the Special Fund for Agro-scientific Research in the Public Interest (20130313006, 201503136), the National Natural Science Foundation of China (31660073), the National Key Research and Development Program of China (2017YFD0200803-04, 2018YFD0800804, 2017YFD0201900) and the Youth Foundation of Xinjiang Academy of Agricultural Sciences (xjnkq-2015002).

\section{References}

Ahmed F, Arthur E, Plauborg F, et al. 2018. Biochar amendment of fluvio-glacial temperate sandy subsoil: Effects on maize water uptake, growth and physiology. Journal of Agronomy and Crop Science, 204(2): 123-136.

Al-Wabel M I, Hussain Q, Usman A R A, et al. 2018. Impact of biochar properties on soil conditions and agricultural sustainability: A review. Land Degradation \& Development, 29(7): 2124-2161. 
Antal M J, Gronli M. 2003. The art, science, and technology of charcoal production. Industrial \& Engineering Chemistry Research, 42(8): 1619-1640.

Barnes R T, Gallagher M E, Masiello C A, et al. 2014. Biochar-Induced changes in soil hydraulic conductivity and dissolved nutrient fluxes constrained by laboratory experiments. PLoS ONE, 9(9): e108340, doi: 10.1371/journal.pone.0108340.

Baronti S, Vaccari F P, Miglietta F, et al. 2014. Impact of biochar application on plant water relations in Vitis vinifera (L.). European Journal of Agronomy, 53: 38-44.

Blanco-Canqui H. 2017. Biochar and soil physical properties. Soil Science Society of America Journal, 81(4): 687-711.

Bruun E W, Petersen C T, Hansen E, et al. 2014. Biochar amendment to coarse sandy subsoil improves root growth and increases water retention. Soil Use and Management, 30(1): 109-118.

Devereux R C, Sturrock C J, Mooney S J. 2012. The effects of biochar on soil physical properties and winter wheat growth. Earth and Environmental Science Transactions of the Royal Society of Edinburgh, 103(1): 13-18.

Dong X H, Yao Z X, Peng T, et al. 2016. Effects of temperature on domparative study of the water characteristiccurve of soil and quartz sand. Research of Soil and Water Conservation, 23(6): 64-68. (in Chinese)

Dugan E, Verhoef A, Robinson S, et al. 2010. Bio-char from sawdust, maize stover and charcoal: impact on water holding capacities (WHC) of three soils from Ghana. Proceedings of the 19th World Congress of Soil Science: Soil solutions for a changing world, Brisbane, Australia, 1-6 August 2010. Symposium 4.2.2 Soil and water-global change: 9-12.

Faloye O T, Alatise M O, Ajayi A E, et al. 2017. Synergistic effects of biochar and inorganic fertiliser on maize (zea mays) yield in an alfisol under drip irrigation. Soil and Tillage Research, 174: 214-220.

Githinji L. 2014. Effect of biochar application rate on soil physical and hydraulic properties of a sandy loam. Archives of Agronomy and Soil Science, 60(4): 457-470.

Glab T, Palmowska J, Zaleski T, et al. 2016. Effect of biochar application on soil hydrological properties and physical quality of sandy soil. Geoderma, 281: 11-20.

Han Q B, Feng S Y, Cao L L, et al. 2015. Thinking about further development of drip irrigation technology and equipment. Journal of Drainage and Irrigation Machinery Engineering, 33(11): 1001-1005. (in Chinese)

Hansen V, Hauggaard-Nielsen H, Petersen C T, et al. 2016. Effects of gasification biochar on plant-available water capacity and plant growth in two contrasting soil types. Soil and Tillage Research, 161: 1-9.

Hardie M, Clothier B, Bound S, et al. 2014. Does biochar influence soil physical properties and soil water availability? Plant and Soil, 376(1-2): 347-361.

Ibrahim H M, Al-Wabel M I, Usman A R A, et al. 2013. Effect of conocarpus biochar application on the hydraulic properties of a sandy loam soil. Soil Science, 178(4): 165-173.

Jacka L, Trakal L, Ourednicek P, et al. 2018. Biochar presence in soil significantly decreased saturated hydraulic conductivity due to swelling. Soil and Tillage Research, 184: 181-185.

Kangoma E, Blango M M, Rashid-Noah A B, et al. 2017. Potential of biochar-amended soil to enhance crop productivity under deficit irrigation. Irrigation and Drainage, 66(4): 600-614.

Karhu K, Mattila T, Bergstrom I, et al. 2011. Biochar addition to agricultural soil increased $\mathrm{CH}_{4}$ uptake and water holding capacity-Results from a short-term pilot field study. Agriculture Ecosystems \& Environment, 140(1-2): 309-313.

Li S L, Wang X, Wang S, et al. 2016. Effects of application patterns and amount of biochar on water infiltration and evaporation. Transactions of the Chinese Society of Agricultural Engineering. Transactions of the Chinese Society of Agricultural Engineering, 32(14): 135-144. (in Chinese)

Liu C, Wang H, Tang X, et al., 2016. Biochar increased water holding capacity but accelerated organic carbon leaching from a sloping farmland soil in China. Environmental Science and Pollution Research, 23(2): 995-1006

Liu X Y, Bian R J, Lu H F, et al. 2018. Biochar for sustainable soil management: Biomass technology and industry from soil perspectives. Bulletin of Chinese Academy of Sciences, 33(2): 184-190. (in Chinese)

Liu Z, Dugan B, Masiello C A, et al. 2016. Impacts of biochar concentration and particle size on hydraulic conductivity and DOC leaching of biochar-sand mixtures. Journal of Hydrology, 533: 461-472.

Lu R K. 2000. Analytical Methods for Soil Agricultural Chemistry ( $3^{\text {rd }}$ ed.). Beijing: China Agricultural Science and Technology Press, 30-33, 56-57, 80-81, 106-107. (in Chinese)

Poormansour S, Razzaghi F. 2018. Effect of biochar and irrigation levels on faba bean productivity. Acta Horticulturae, 1190 : $157-162$.

Qi R P, Zhang L, Yan Y H, et al. 2015. Effects of biochar addition into soils in semiarid land on water infiltration under the condition of the same bulk density. Chinese Journal of Applied Ecology, 31(16): 128-134. (in Chinese)

She D, Sun X, Gamareldawla A H D, et al. 2018. Benefits of soil biochar amendments to tomato growth under saline water irrigation. Scientific Reports, 8: 14743, doi: 10.1038/s41598-018-33040-7. 
Suliman W, Harsh J B, Abu-Lail N I, et al. 2017. The role of biochar porosity and surface functionality in augmenting hydrologic properties of a sandy soil. Science of the Total Environment, 574: 139-147.

Wang D, Li G, Mo Y, et al. 2017. Effect of planting date on accumulated temperature and maize growth under mulched drip irrigation in a middle-latitude area with frequent chilling injury. Sustainability, 9(9): 1500, doi: 10.3390/su9091500.

Wang D D, Zheng J Y, Yan Y H, et al. 2013. Effect of biochar application on soil water holding capacity in the southern region of Ningxia. Journal of Soil and Water Conservation, 27(2): 101-109. (in Chinese)

Wang R Y, Wei Y X, Liu H, et al. 2018. Influences of biochar on hydrodynamic parameters of meadow black soil. Transactions of the Chinese Society for Agricultural Machinery, 49(7): 186-194. (in Chinese)

Xiao Q, Zhang H P, Shen Y F, et al. 2015. Effects of biochar on water infiltration, evaporation and nitrate leaching in semi-arid loess area. Transactions of the Chinese Society of Agricultural Engineering, 31(16): 128-134. (in Chinese)

Xiao Y, Yang S, Xu J, et al. 2018. Effect of biochar amendment on methane emissions from paddy Field under water-saving irrigation. Sustainability, 10(5): 1-13.

Xing X G, Zhao W G, Ma X Y, et al. 2015. Study on soil shrinkage characteristics during soil water characteristic curve measurement. Journal of Hydraulic Engineering, 46(10): 1181-1188. (in Chinese)

Xu J, Niu W Q, Li Y, et al. 2015. Effects of biochar addition on soil water movement under moistube-irrigation. Water Saving Irrigation, 12: 64-68. (in Chinese) 